\title{
Exploring the Relationships between Students' Online Interactive Activities and Their Views of the Nature of Scientific Theories
}

\author{
P. J. Li and H.-Y. Hong
}

\begin{abstract}
The purpose of this study was to investigate whether engaging students in computer supported collaborative activities in a knowledge-building environment could help them develop a deeper understanding of the nature of scientific theories. Findings indicated: 1) students' views of the nature of scientific theories significantly changed, becoming more constructivist-oriented toward the end of the semester; 2) there was a statistically significant relationship between students' online interactive activities and their enhanced understanding of the nature of scientific theories. In sum, engaging students in computer supported collaborative activities in a knowledge-building environment seems to be supportive in helping students develop a more informed view of the nature of scientific theories.
\end{abstract}

Index Terms-Knowledge-building, computer supported collaborative learning, nature of scientific theory.

\section{INTRODUCTION}

Previous research shows that promoting students' understanding of the nature of science can help them better learn science [1]-[3]. Pamquist and Finley [4] developed a questionnaire to assess students' views of the nature of science using two broad categories including 'traditional' and 'contemporary' views. Basically, a 'traditional' view assumed that all knowledge and theories came from objective observation. As such, scientific theories are seen as more certain and authoritative and perhaps can only be changed when new and contradictory facts are "found" or "discovered." In contrast, 'contemporary' views see theory as a humanly "invented" reality. As such, theories are deeply influenced by social and cultural factors. Some researchers argue that possessing a more 'contemporary' and constructivist-oriented view of the nature of science is helpful for students in developing the high-level thinking and problem-solving abilities necessary for advanced science inquiry learning [5], [6].

However, research pertaining to the investigation of students' understanding of the nature of science also showed that many students still see scientific knowledge and theories as absolutely objective and certain [7], [8]; as such, they tend to believe that science learning is equivalent to rote learning (e.g. memorizing a body of related scientific facts). Accordingly, science teaching is seen as highlighting the "telling" of knowledge rather than deeper understanding.

Consequently, students usually do not know how to apply

Manuscript received May 17, 2014; revised July 30, 2014.

Pei Jung $\mathrm{Li}$ and Huang-Yao Hong are with National Chengchi University, Taiwan (e-mail: 101152005@nccu.edu.tw). knowledge they acquire from textbooks to real life problemsolving situations; sometimes they even lose their interest in science learning due to repetitive learning practices. It is indeed necessary to further explore alternative ways of developing more effective learning environments that can avoid passive learning and knowledge feeding, and can better motivate students to engage in more self-initiated and self-directed science learning. Doing so would more likely guide them to serve as knowledge workers and engage in more knowledge-building (rather than knowledge-telling) activities for more effective science learning. To this end, this study adopted an instructional approach that is designed based on a knowledge-building (KB) theory [9].

This theory was originally proposed by Carl Bereiter and Marlene Scardamalia [9]. It is a social process that fosters collaborative activities in order to advance community or group knowledge (i.e. collective understanding of an inquiry topic pursued by a whole class as a learning community). To foster such activities 12 knowledge building principles that highlight intentional, self-directed knowledge work were developed [10]. As a principle-based approach, KB is different from other approaches that emphasize knowledgetelling (i.e. acquiring and accumulating knowledge as a primary instructional goal) and procedure-based, step-bystep instructional activities. Instead, student learning is guided only by principles; they need to generate ideas to solve real-life problems. For example, the principle of "real ideas and authentic problems" argues for the importance of using real-world problems to engage students in working with their own (self-generated) ideas as a way to initiate more active and self-regulated learning. This is a main reason why it is different from the kind of procedure-based learning that usually involves fixed instructional steps or activities, pre-defined textbook knowledge and a wellstructured curriculum, and, more importantly, standardized tests.

Building on these $\mathrm{KB}$ principles as instructional guideposts, the participating students in this study worked in an online KB environment called Knowledge Forum ${ }^{\mathrm{TM}}$. As an online platform, Knowledge Forum ${ }^{\mathrm{TM}}$ enables openended discussion and inquiry. Students usually start with brain-storming activities in order to decide an inquiry topic that is related to their learning interests. Then, they generate some rough, spontaneous ideas of ways to address these topics or problems, and ask questions and respond to one another's questions by utilizing their prior knowledge and living experiences. Then, they continue to work with their initial ideas for sustained improvement. The main instructional goal was to guide students to role-play scientists-just like scientists they can work with their 
initial ideas and gradually develop them into more reliable scientific knowledge by means of exploring more coherent explanations for some observed natural phenomena. As students are guided to work with ideas and try to transform their ideas into some theory-like explanations, it is hypothesized that engaging students in $\mathrm{KB}$ can help them develop more informed and constructivist-oriented views of the nature of scientific theories.

\section{METHOD}

\section{A. Participants and Context}

Participants were Taiwanese college students who study in a general education course on the natural sciences. The duration of the course was 18 weeks (i.e. a whole semester). At the beginning of the course, the participating students discussed some science issues they were interested in inquiring about in the Knowledge Forum ${ }^{\mathrm{TM}}$. Next, they used the key design features developed in the Knowledge Forum $^{\mathrm{TM}}$ to conduct their online inquiry, e.g. by using the built-in KB scaffolds to develop their ideas. These scaffolds included the following: 1) "I need to understand..."; 2) "My theory is..."; 3) "This theory cannot explain..."; 4) "New information..."; 5) "A better theory..."; and 6) "Putting our knowledge together...". The scaffolds were customizable for students wanting to remove or change old ones or add new ones. These design features were originally designed based on the above-mentioned KB principles. The overall goal in the community was to advance collective knowledge or understanding about a given inquiry theme or topic in the community. Fig. 1 shows a screenshot of a view (i.e. a problem-solving and discussion space) from the Knowledge Forum $^{\mathrm{TM}}$

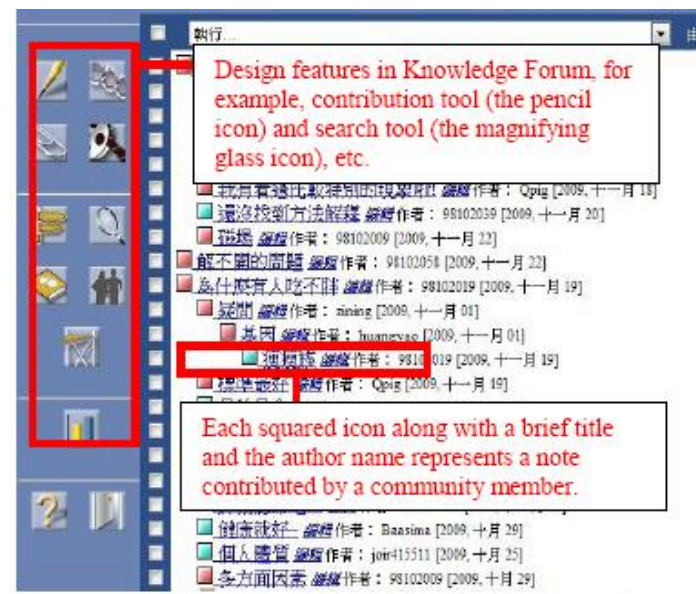

Fig. 1. An example of some design features with some discussion activities listed as note titles in a Knowledge Forum ${ }^{\mathrm{TM}}$ view (i.e. a collective discussion and problem-solving space).

\section{B. Data Source and Analysis}

Data collection in the present research included an openended survey and participating students' online interaction activities in the Knowledge Forum ${ }^{\mathrm{TM}}$. The survey was selfdeveloped to assess participating students' understanding or views of the nature of the scientific theories. To this end, a set of open questions concerning the nature, source, and purpose of scientific theories (e.g. "What is a scientific theory?" and "Where does a scientific theory come from?) was developed. The survey was then administered at the beginning and at the end of the course. As for the online interactive activities, all online interaction $\log s$ were automatically recorded in a database.

In terms of analysis, the pre- and post-course surveys were assessed using a coding scheme that emerged from an open-coding process [11]. The first author reflectively read and re-read all the notes online in order for coding themes to emerge progressively over time. The five coding themes which finally emerged were: "Theory-independent vs. Theory-dependent"; "Single research method vs. Diverse research methods"; "Value-free vs. Value-laden"; "Discovery vs. Invention"; and "Permanent vs. Temporary" (see Table I). The surveys were then further rated with a five-point Likert scale against each specific coding theme. Using the "Permanent vs. Temporary" coding theme as an example, point one indicated that the participant tended to see scientific theory as an infinite and unchangeable epistemic entity, whereas point five referred to a perspective that sees a scientific theory as a dynamic and improvable (or replaceable) epistemic entity (i.e. it can be refined or modified by a better theory). The coding results were then statistically examined using paired-samples t-tests. This was done to examine if there were any changes in the views of the nature of scientific theories over time.

Further, participating students' activities in the Knowledge Forum ${ }^{\mathrm{TM}}$ was analyzed by a tool called the Analytic Toolkit (ATK) that was embedded in the forum for the purpose of obtaining quantitative data regarding online activities (e.g. the number of notes posted, read, linked, etc.; namely, students' online interactions). Descriptive analysis was computed to show how each student performed the activity online. Relational analysis was also computed to examine whether there were any correlations between different online activities (e.g. number of notes posted and number of notes read).

Finally, the relationships between students' online activities and their views (or understanding) of the nature of scientific theories was further examined. For this specific analysis, weeks were used as the unit of analysis. The entire semester was first divided into two periods (each lasting for nine weeks) with mid-term examination being treated as the separation point to observe pre- and post-survey view changes for the whole semester. Then, to understand the relationships between online forum activities and participants' pre- and post-survey view changes (regarding the nature of scientific theories), participants' online activities were categorized into four main types of online activities based on their characteristics, as follows: 1) contribution activity (i.e. number of notes contributed); 2) reading activity (i.e. number of notes read and total number of times that all notes were read); 3) improvement activity (i.e. number of notes revised and number of times scaffolds were used); and 4) collaborative activity (i.e. percentage of notes connected with others' notes and percentage of builton notes). All four types of online activities were then further summed up and averaged to obtain a mean online activity rating. Using this mean number, students were further divided into "high vs. low" online participation.

Then, correlation analysis was conducted to observe whether there was a statistical correlation between 
participants' view changes and their online participation ("high vs. low" online activities). It was posited that the more active students were engaging in online activities, the more likely they would also be able to develop more constructivist-oriented views of the nature of scientific theories.

\section{RESULTS}

\section{A. Views of the Nature of Scientific Theories}

As shown in Fig. 2, the results indicated that there were significant view changes in the five categories between presurvey and post-survey results. The detailed statistics are shown as follows: 1) for the "Theory-independent vs. Theory-dependent" category, $t=-4.77, p<.001 ; 2)$ for the "Single research method vs. Diverse research methods" category, $t=-6.53, p<.001 ; 3)$ for the "Value-free vs. Valueladen" category, $t=-3.05, p<.05 ; 4)$ for the "Discovery vs. Invention" category, $t=-3.80, \quad p<.001$; and 5) for the "Permanent vs. Temporary" category, $t=-4.35 ; p<.001$.

\begin{tabular}{|c|c|c|}
\hline Category & & Description \\
\hline \multirow{2}{*}{$\begin{array}{l}\text { Theory- } \\
\text { independent } \\
\text { vs. } \\
\text { Theory- } \\
\text { dependent }\end{array}$} & $\begin{array}{l}\text { Theory- } \\
\text { independent }\end{array}$ & $\begin{array}{l}\text { An observation is theory- } \\
\text { independent. A theory is confirmed } \\
\text { thorough experiments and is viewed } \\
\text { as purely objective. }\end{array}$ \\
\hline & $\begin{array}{l}\text { Theory- } \\
\text { dependent }\end{array}$ & $\begin{array}{l}\text { An observation is theory-dependent. } \\
\text { A theory is a product that can be } \\
\text { influenced by social and cultural } \\
\text { factors. }\end{array}$ \\
\hline \multirow{2}{*}{$\begin{array}{l}\text { Single } \\
\text { research } \\
\text { method vs. } \\
\text { Diverse } \\
\text { research } \\
\text { methods }\end{array}$} & $\begin{array}{l}\text { Single } \\
\text { research } \\
\text { method }\end{array}$ & $\begin{array}{l}\text { The generation of a theory involves } \\
\text { repetitive validation usually using a } \\
\text { single research method. Most are } \\
\text { completed in a laboratory with } \\
\text { equipment. }\end{array}$ \\
\hline & $\begin{array}{l}\text { Diverse } \\
\text { research } \\
\text { methods }\end{array}$ & $\begin{array}{l}\text { The generation of a theory is from } \\
\text { trials of various research methods, } \\
\text { including, for example, experiments, } \\
\text { debate, literature reviews, and } \\
\text { discussion. }\end{array}$ \\
\hline \multirow{2}{*}{$\begin{array}{l}\text { Value-free vs. } \\
\text { Value-laden }\end{array}$} & Value-free & $\begin{array}{l}\text { Scientific theory development is not } \\
\text { influenced by social and cultural } \\
\text { values. }\end{array}$ \\
\hline & Value-laden & $\begin{array}{l}\text { Scientific theory development is } \\
\text { influenced by social and cultural } \\
\text { values. }\end{array}$ \\
\hline \multirow{2}{*}{$\begin{array}{l}\text { Discovery } \\
\text { vs. } \\
\text { Invention }\end{array}$} & Discovery & $\begin{array}{l}\text { A theory is discovered and it does } \\
\text { not embody any personal } \\
\text { interpretation. }\end{array}$ \\
\hline & Invention & $\begin{array}{l}\text { A theory is a subjective result } \\
\text { combined with personal imagination } \\
\text { and interpretation. }\end{array}$ \\
\hline \multirow{2}{*}{$\begin{array}{l}\text { Permanent } \\
\text { vs. } \\
\text { Temporary }\end{array}$} & Permanent & $\begin{array}{l}\text { A theory represents the authoritative } \\
\text { and perpetual existence of certain } \\
\text { truth. }\end{array}$ \\
\hline & Temporary & $\begin{array}{l}\text { A theory is the best explanation for } \\
\text { the time being and can be refuted or } \\
\text { improved by a better explanation in } \\
\text { the future. }\end{array}$ \\
\hline
\end{tabular}

In brief, participants' understanding or views of the nature of scientific theories were initially inclined to treat theories as objective and permanent truths discovered by scientists. Toward the end of the semester, however, their views became more constructivist-oriented and diversified; they tended to see theories as tentative but best-available explanations for some observed phenomena and they also tended to consider theories as modifiable or falsifiable epistemic entities.

\section{B. Relationship between Students' Online Activities and Their View Changes}

As baseline information, participants' basic online activities are described as follows: 1) average number of notes contributed per student to the forum $(M=21.8), 2)$ average percentage of notes being linked to other notes was $(M=77.1 \%), 3)$ average number of notes being read per student was $(M=264.4), 4)$ average number of notes being revised per student was $(M=4.8)$, and 5) average numbers of scaffolds being used per student was $(M=16.8)$. The correlations among these online activities are presented in Table II which shows that 13 out of 15 correlations are statistically significant $(.29<r<.95)$. The findings suggest that the more actively engaged they were in one online activity (e.g. note contribution), the more likely the participating students would also be engaged in another activity (e.g. note reading).

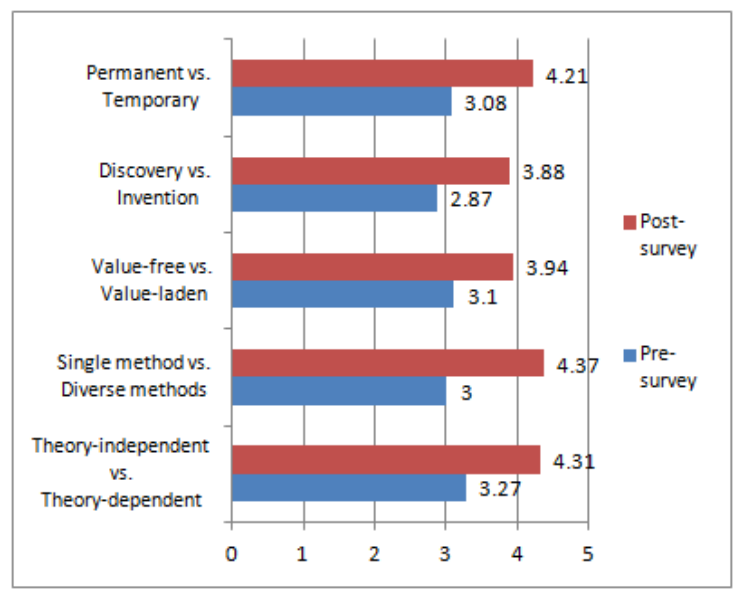

Fig. 2. Students' pre- and post-survey results regarding their views of the nature of scientific theories.

TABLE II: CORRELATIONS AMONG KEY ONLINE ACTIVITIES

\begin{tabular}{l|c|c|c|c|c|c}
\hline & 1 & 2 & 3 & 4 & 5 & 6 \\
\hline $\begin{array}{l}\text { 1. \# of notes } \\
\text { contributed }\end{array}$ & 1 & $\begin{array}{c}0.46 \\
* *\end{array}$ & $0.37 * *$ & $0.86^{* *}$ & $0.69 * *$ & $0.47 * *$ \\
\hline $\begin{array}{l}2 . \% \text { of } \\
\text { notes linked }\end{array}$ & & 1 & 0.19 & $0.38^{* *}$ & $0.46^{* *}$ & $0.95^{* *}$ \\
\hline $\begin{array}{l}3 . \# \text { of note } \\
\text { revisions }\end{array}$ & & 1 & $0.47 * *$ & $0.29 *$ & 0.20 \\
\hline $\begin{array}{l}4 . \# \text { of } \\
\text { scaffolds } \\
\text { used }\end{array}$ & & & & 1 & $0.69 * *$ & $0.38^{* *}$ \\
\hline $\begin{array}{l}5 . \# \text { of notes } \\
\text { read }\end{array}$ & & & & & 1 & $0.43 * *$ \\
\hline $\begin{array}{l}6 . \# \text { of built- } \\
\text { on notes }\end{array}$ & & & & & & 1 \\
\hline
\end{tabular}

Furthermore, as shown in Fig. 3, investigation was conducted regarding the relationships between participating students' online activities and the changes in their views of the nature of scientific theories. In this particular analysis, the participating students were divided into two groups based on the degree of changes in their views of the nature of scientific theories, using pre- and post-survey view change scores ("low change" group vs. "high change" group). On the other hand, for online performance, all forum activities were divided into four different categories (including contribution activity, reading activity, improvement activity, and collaboration activity). Next, each category of the activity was divided into high- 
frequency and low-frequency activities. For statistics purposes, a crosstab analysis was then conducted to examine the relationship between view change ("high vs. low" change) and online activities ("high vs. low" frequency). Overall, the results showed that there was a statistically significant positive correlation $\left(X^{2}=4.93, p<.05\right)$. In other words, participants' change towards more constructivistoriented views of the nature of scientific theories towards the end of the semester was highly related to the frequency of activities in the forum in this study.

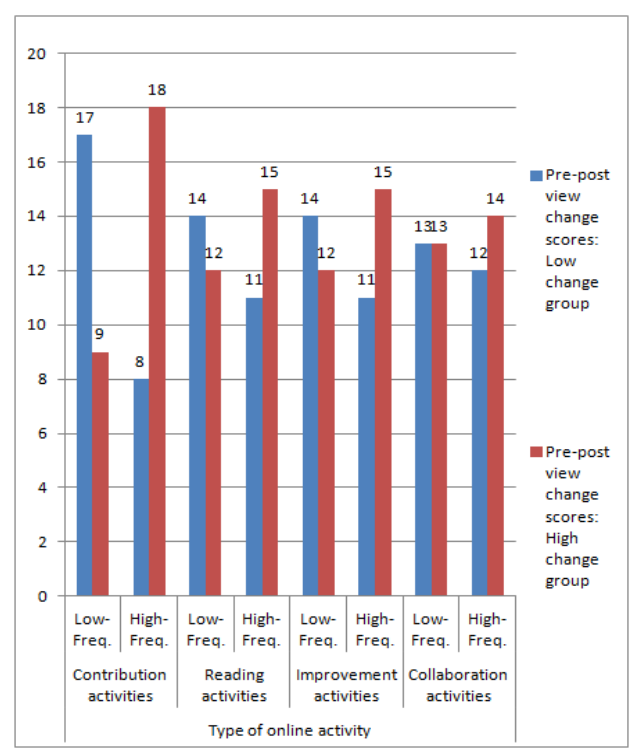

Fig. 3. Results of participants' view change ("low change" group vs. "high change" group) and their online activities ("high vs. low" frequency activities).

\section{SUMMARY AND CONCLUSION}

The purpose of this study was to investigate whether engaging college students in computer-supported collaborative knowledge work in an online environment designed based on KB pedagogy could help them develop more informed, constructivist-oriented views of the nature of scientific theories.

In summary, there were two main findings. Firstly, the results indicated that after working collaboratively in a $\mathrm{KB}$ environment for a semester, participants' views of the nature of scientific theories changed significantly. Specifically, they became less likely to see scientific theories as absolute truths discovered by scientists as authoritative figures. Instead, they became more willing to see scientific theories as "invented reality" [12] that is value-laden and may be subjectively influenced by social and cultural factors. Secondly, the results also showed that online inquiry activities were quite consistent throughout the whole semester, which were significantly correlated with participants' view changes. In conclusion, engaging in online $\mathrm{KB}$ activities was found to be associated with students' change of views in tending to see scientific theories as improvable, epistemic entities. Further studies will continue to examine whether there is also causal relationships between the two variables at issue.

\section{ACKNOWLEDGEMENT}

Support for writing this article was provided, in part, from Taiwan's National Science Council (NSC) Grants NSC \#101-2628-S-004-001-MY3. The opinions expressed in this article are those of the authors only and do not reflect the opinions of the NSC.

\section{REFERENCES}

[1] N. B. Songer and M. C. Linn, "How do students view of science influence knowledge integration?" Journal of Research in Science Teaching, vol. 28, no. 9, pp. 761-784, 1991.

[2] C. C. Tsai, "An analysis of scientific epistemological beliefs and learning orientations of Taiwanese eighth graders," Science Education, vol. 82, no. 4, pp. 473-789, 1998.

[3] Y. M. Lee, "A research of elementary students' views toward the nature of science," M.S. thesis, Taipei Municipal University of Education, Taipei, Taiwan, 2002.

[4] B. C. Palmquist and F. N. Finley, "Preservice teachers' views of the nature of science during a post-baccalaureate science teaching program," Journal of Research in Science Teaching, vol. 34, no. 6, pp. 595-615, 1997.

[5] N. G. Lederman, "Students' and teachers' conceptions of the nature of science: A review of the research," Journal of Research in Science Teaching, vol. 29, no. 4, pp. 331-359, 1992.

[6] H. Y. Weng and H. L. Duan, "Revelation and application of the nature of science in science education," Science Education Monthly, vol. 201, pp. 2-16, 1997.

[7] F. Abd-El-Khalick, R. L. Bell, and N. G. Lederman, "The nature of science and instructional practice: Making the unnatural natural," Science Education, vol. 82, no. 4, pp. 417-436, 1998.

[8] J. J.Gallagher, "Prospective and practicing secondary school science teachers' knowledge and beliefs about the philosophy of science," Science Education, vol. 75, no. 1, pp. 121-133, 1991.

[9] M. Scardamalia and C. Bereiter, "Knowledge building: Theory, pedagogy, and technology," in Cambridge Handbook of the Learning Sciences, K. Sawyer, Ed., Cambridge: Cambridge Univ, 2006, pp. $97-$ 118.

[10] M. Scardamalia, "Collective cognitive responsibility for the advancement of knowledge," in Liberal Education in a Knowledge Society, B. Smith, Ed., Chicago: Open Court, 2002, pp. 67-98.

[11] J. Corbin and A. Strauss, Basics of Qualitative Research: Techniques and Procedures for Developing Grounded Theory, SAGE Publications, Inc., 2008.

[12] W. M. Roth and K. B. Lucas, "From 'truth' to 'invented reality': A discourse analysis of high school physics students' talk about scientific knowledge," Journal of Research in Science Teaching, vol. 34, no. 2, pp. 145-179, 1997.

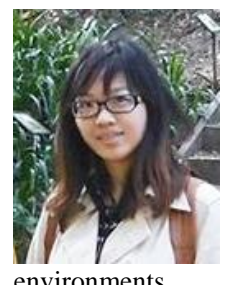

Pei Jung Li received her Ed.M. (master degree of education) in Graduate School of Education at National Chengchi University, Taiwan. Her undergraduate major is educational psychology. She is currently teaching as a student teacher at $\mathrm{Ci}$-Xin Waldord School, in Yi-Lan County, Taiwan. Her research interest focuses on epistemology, educational technology, and computer-assisted learning environments.

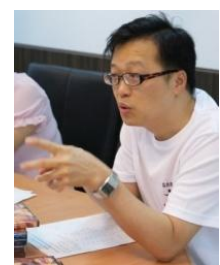

Huang-Yao Hong is a professor in the Department of Education, National Chengchi University, Taiwan. He received his Ed.M. and Ed.D. in the area of instructional technology and media from Teachers College, Columbia University, New York, United States. He currently teaches courses about instructional design, learning technology, and knowledge building theory, and his research focuses on knowledge building in computer supported multimedia environments and related design issues. 